\title{
Communities of practice in healthcare: A framework for managing knowledge sharing in operations
}

Jørgensen, Rasmus; Scarso, Enrico; Edwards, Kasper; Ipsen, Christine

Published in:

Knowledge and Process Management

Link to article, DOI:

10.1002/kpm.1590

Publication date:

2019

Document Version

Peer reviewed version

Link back to DTU Orbit

Citation (APA):

Jørgensen, R., Scarso, E., Edwards, K., \& Ipsen, C. (2019). Communities of practice in healthcare: A framework for managing knowledge sharing in operations. Knowledge and Process Management, 26(2), 152-162.

https://doi.org/10.1002/kpm.1590

\section{General rights}

Copyright and moral rights for the publications made accessible in the public portal are retained by the authors and/or other copyright owners and it is a condition of accessing publications that users recognise and abide by the legal requirements associated with these rights.

- Users may download and print one copy of any publication from the public portal for the purpose of private study or research.

- You may not further distribute the material or use it for any profit-making activity or commercial gain

- You may freely distribute the URL identifying the publication in the public portal

If you believe that this document breaches copyright please contact us providing details, and we will remove access to the work immediately and investigate your claim. 


\title{
Communities of Practice in Healthcare: A Framework for Managing
}

Knowledge Sharing in Operations

Rasmus Jørgensen, Ph.D. student; ${ }^{1}$ Enrico Scarso, Professor; ${ }^{2}$ Kasper Edwards, Senior Researcher; ${ }^{1}$ and Christine Ipsen, Assistant Professor ${ }^{1}$

${ }^{1}$ Implementation and performance management, Technical University of Denmark, DTU Management Engineering, Kgs. Lyngby, Denmark

2 Department of Management and Engineering, University of Padua

rajor@dtu.dk

\section{PAPER TASKS}

\begin{abstract}
Communities of Practice (CoPs) have been adopted by several industries, in particular healthcare, and researchers have proposed explanatory frameworks and guidelines for development. However, operations managers are left with sparse research-based advice on how to develop CoP due to a lack of empirical studies from such a context. In response this paper proposes and tests a framework for intentional development of CoPs in healthcare operations. The proposed framework is structured in six steps which incorporate seven factors for CoP development as identified in the literature. A double case study test demonstrates that the proposed framework can be applied to develop CoPs within operations, resulting in knowledge sharing between $\mathrm{CoP}$ participants, creation of new knowledge, and improvement of practice. In particular, the tests find the following steps to be especially crucial for $\mathrm{CoP}$ development: an introduction to the manager of the functions and benefits of CoPs to ensure resource allocation (e.g. time to participate and a meeting room), choosing a practice with relevance for manager and employees, appointing a coordinator, and inviting employees to participate voluntarily. This paper contributes to CoP theory with explanations of how and why specific actions develop $\mathrm{CoP}$ within operations. The contribution to practitioners is a step-by-step framework to intentionally develop CoPs within operations to improve knowledge sharing and practice improvement.
\end{abstract}

Keywords: communities of Practice, knowledge sharing, operations, knowledge management, case study

\section{Introduction}

Process efficiency and effectiveness are significantly influenced by the knowledge developed, shared, and applied by employees in operations (Hislop, 2013). An organisation must therefore make deliberate choices about how to organise knowledge sharing within their operations context. The operations level in public healthcare is characterised by 24-hour-day, seven-day-week shifts, few occasions to meet, the need for compliance, and small groups of employees with specific competencies. These factors must be carefully considered when organising knowledge sharing as they limit opportunities for face-to-face meetings and require task standardisation. 
Written guidelines are a frequently used tool for sharing knowledge in operations; however, their impact can be limited (Bhattacharyya, Reeves, \& Zwarenstein, 2009), particularly as they rely solely on explicit knowledge and separate knowledge from the used context and the social system (Lave \& Wenger, 1991). Indeed, knowledge has both tacit and explicit elements which require distinctly different sharing methods (Hislop, 2013). Tacit knowledge sharing requires face-to-face meetings for interpretation, negotiation, and storytelling to take place (Orr, 1996; Wenger, Snyder, \& McDermott, 2002), whereas explicit knowledge can be shared via information processing methods such as guidelines (Hislop, 2013; Zack, 2000). A coherent approach to operations knowledge sharing should therefore include complementary methods for both tacit and explicit knowledge sharing.

Tacit knowledge sharing in organisations is associated with Communities of Practice (CoPs), and while some scholars describe a $\mathrm{CoP}$ as an activity which is self-organised by employees (Gabbay \& le May, 2004; Orr, 1996), others suggest that a CoP can be intentionally developed to improve organisational knowledge sharing (Aljuwaiber, 2016; Barbour, Armstrong, Condron, \& Palermo, 2018; Wenger et al., 2002). CoPs have been intentionally developed in a variety of contexts: finance (McDermott \& Archibald, 2010), engineering (Schenkel \& Teigland, 2008), healthcare (Li et al., 2009; Ranmuthugala et al., 2011), tourism (Akkerman, Petter, \& Laat, 2008), and manufacturing (Yamklin \& Igel, 2012). Explanatory frameworks have been proposed to shed light on the critical success factors for developing CoPs (Scarso, Bolisani, \& Salvador, 2009), to describe connections between CoP processes and organisational processes (McKellar, Pitzul, Yi, \& Cole, 2014), and to evaluate CoPs (Verburg \& Andriessen, 2006). While the significance of CoPs for knowledge flow and application in healthcare operations has been highlighted (Perrott, 2015), few studies have explored how a CoP can be intentionally developed within healthcare operations. Additionally, scholars have called for case studies to further develop CoP theory in a general business context (Aljuwaiber, 2016) and in public health (Barbour et al., 2018). We address this gap by proposing and testing a framework for intentional $\mathrm{CoP}$ development in a specific case within operations which evaluates the CoP on knowledge sharing, new knowledge creation, and practice improvement. Consequently, the research questions of the study are as follows: How can CoP be purposefully developed in operations? What steps are necessary to purposefully develop CoP within healthcare operations?

The proposed framework was synthesised from CoP literature and tested twice in a 10-month period in a hospital blood analysis unit in which employees operate automatic analysis equipment. The two tests concerned two different practices: Test 1 focussed on a maintenance procedure, while test 2 concerned a start-up procedure.

\section{Communities of Practice}

A Community of Practice is defined as a 'group of people who share a concern, a set of problems, or a passion about a topic, and who deepen their knowledge and expertise in this area by interacting on an ongoing basis' (Wenger et al., 2002). The term Community of Practice was coined in a descriptive study emphasising the importance of learning in the context of doing something together with others (Lave \& Wenger, 1991). The interest in how work, knowledge, and employee relations are connected and their influence on organisational performance has yielded numerous studies of 
CoP in the organisational context, meta studies, and explanatory frameworks (Aljuwaiber, 2016; McKellar et al., 2014). The literature analysis forming the basis for the framework identified seven critical factors for CoP development.

\section{Factor 1 (F1): Voluntary participation}

While early studies affirmed that CoPs are self-organised by employees who share an interest and that the CoPs do not exist due to lack of management support (Gabbay \& le May, 2004; Lave \& Wenger, 1991; Orr, 1996), the opinion has gained currency that CoPs can be deliberately created and managed (Wenger, 2004; Wenger et al., 2002). In some cases, pre-existing and 'slumbering' CoPs can be leveraged when intentionally developing CoPs by 'manipulating emergence' of new CoPs (Kislov, Walshe, \& Harvey, 2012) and relying on the pre-existing network and social capital (Fung-Kee-Fung, Boushey, Watters, et al., 2013; Iaquinto, Ison, \& Faggian, 2011). By making CoP participation voluntary, the employees are allowed to decide whether the CoP is relevant for their jobs (Fung-Kee-Fung, Boushey, \& Morash, 2013; Hemmasi \& Csanda, 2009; Scarso et al., 2009) and to choose if the CoP focus is of practical interest to them (Akkerman et al., 2008; Wolf, Späth, \& Haefliger, 2011). In this way, the CoP should include only genuinely involved and interested employees, which favours its successful development (Wenger, 2004).

\section{Factor 2 (F2): CoP Coordination}

Assigning a person informal authority and making that person responsible for CoP well-being, practical tasks, stakeholder contacts, and meeting coordination is frequently found in association with successful CoPs (Aljuwaiber, 2016; Li et al., 2009). Such a role is named differently across studies: coordinator (Iaquinto et al., 2011; Wenger et al., 2002), facilitator (Cordery et al., 2015; Scarso et al., 2009; Schenkel \& Teigland, 2008; Wolf et al., 2011), knowledge broker (Conklin, Lusk, Harris, \& Stolee, 2013), leader (Probst \& Borzillo, 2008), and discussant fellow (Rowley, Morriss, Currie, \& Schneider, 2012). A beneficial definition comes from Conklin et al. (2013), who have described how knowledge brokers engage in a set of relational, technical, and analytical activities which help CoPs to develop and operate. The responsibilities of the roles varies and can include practical tasks comprising coordinating meetings rooms and other meeting facilities (Akkerman et al., 2008; Iaquinto et al., 2011; Wenger et al., 2002), facilitating inter-CoP relationships (Akkerman et al., 2008; Barwick, Peters, \& Boydell, 2009; Conklin et al., 2013), promoting inter-CoP discussions (Barwick et al., 2009; Probst \& Borzillo, 2008), encouraging participation (Iaquinto et al., 2011), recruiting new members (Wolf et al., 2011), and liaising with stakeholders and collaborators (Rowley et al., 2012; Wenger et al., 2002).

\section{Factor 3 (F3): Allocation of time}

Within the operational context, employees are often assigned to a shift and, in contrast to knowledge workers (e.g., engineers) who have some influence over time and tasks, they are dependent on someone to cover their shift in instances of absence. Consequently, time to participate in the CoP must be allocated by an operations employee's manager, making participation a question of resource allocation and management priorities. Still, similarities exist across contexts, and having the necessary time to participate in the $\mathrm{CoP}$ has been found to be important in healthcare (FungKee-Fung, Boushey, Watters, et al., 2013), construction (Schenkel \& Teigland, 2008), and automotive engineering (Wolf et al., 2011). Several studies have related successful CoPs with the 
presence of a sponsor manager who determines the time available for CoP participation either through direct allocation or indirect support (Iaquinto et al., 2011; McDermott \& Archibald, 2010; Probst \& Borzillo, 2008).

\section{Factor 4 (F4): Allocation of a room}

$\mathrm{CoP}$ is a social phenomenon, hence physical interaction between $\mathrm{CoP}$ members is regarded as important for its success (Fung-Kee-Fung, Boushey, Watters, et al., 2013; Iaquinto et al., 2011; Orr, 1996; Wenger et al., 2002), while reduced face-to-face interaction is found to have negative effects on CoP performance (Schenkel \& Teigland, 2008). A meeting between CoP participants must provide a risk-free zone which caters for participants' ability to ask questions without risk of sanction (Borzillo, 2009), enables in-depth and undisturbed discussions (Orr, 1996), and facilitates a collaborative work effort (Fung-Kee-Fung, Boushey, \& Morash, 2013). A designated meeting room in which the CoP participants can fulfil this function.

\section{Factor 5 (F5): Focussed organisational knowledge responsibility}

A defining element of a $\mathrm{CoP}$ is that a group of people share an interest in a topic (Wenger et al., 2002). Intentional CoP development involves a chosen focus area, and the personal interest of the individual is the source of motivation for participating (Probst \& Borzillo, 2008; Wenger et al., 2002). Additionally, providing the CoP with a formal decision authority to implement improvements to the practice appears to be a motivational factor for participating in the $\mathrm{CoP}$ as individual engagement makes a difference (Wolf et al., 2011). Furthermore, the implementation of improvement suggestions means that the $\mathrm{CoP}$ outcome is not limited to participants but extends to all employees performing the practice. The decision authority over practice can be formalized by making the CoP responsible for implementing practice improvements; for example, update the guidelines (Cordery et al., 2015). By having the CoP implement improvement suggestions, the organisational knowledge repository is continuously developed and maintained; a collaborative implementation effort also develops interpersonal relationships between participants (Lesser \& Storck, 2001).

\section{Factor 6 (F6): Choosing Information and Communication Technology (ICT)}

ICT is important for both communication and relationships between CoP participants and for the implementation of improvement suggestions in the organisational knowledge repository (Lesser \& Storck, 2001). Participants cannot always communicate face-to-face because of factors such as round-the-clock shifts in operations, and in other contexts geographical distances or time differences influence how communication can take place and, consequently, the choice of ICT. The assigned ICT must therefore be aligned with employees' preferences (e.g., communicating via email if employees are familiar with this technology) (Scarso et al., 2009). In most modern organisations knowledge management relies on the use of ICT (Hislop, 2013), and allocation of ICT (e.g., a camera to take pictures and laptop to write text, and possible system access) makes the CoP capable of implementing improvement suggestions. 


\section{Factor 7 (F7): Soft management approach}

The role of management changes depending on the method for managing knowledge. For a CoP, management is characterised as 'weak' because its role is to support and develop relationships between employees, whereas the use of prescriptive guidelines is associated with 'strong management' which enforces desired behaviour (Hislop, 2013). Hence, the management of a CoP is typically characterised as using a 'soft-hand' approach (Aljuwaiber, 2016; McDermott \& Archibald, 2010; Wenger et al., 2002) in which managers assign resources and decision authority (Probst \& Borzillo, 2008; Wolf et al., 2011). In some cases, management is actively involved in the identification of a practice that becomes the focus of a $\mathrm{CoP}$ and employees can volunteer to participate in the CoP (Akkerman et al., 2008; Iaquinto et al., 2011)

Informed by the literature analysis and considering the operations context (round-the-clock shifts, few people who know the practice, and little time to meet), the critical factors are synthesised into a framework for intentional CoP development (see Figure 1).

\section{Proposing the Framework}

\subsection{The six steps}

The proposed framework for intentional $\mathrm{CoP}$ development within operations comprises six sequential steps Figure 1). A prerequisite is the presence of a CoP promoter who, in the analysed cases, was one of the researchers (Rasmus Jørgensen (RJ)). The framework adopts the perspective of a senior manager or consultant who is to implement a CoP.

\begin{tabular}{|l|}
\hline STEP 1- Manager introduction \\
\hline Informed by F3, F4, F7 \\
\hline STEP 2 - Practice definition \\
\hline Informed by F5 \\
\hline STEP 3 - Coordinator identification \\
\hline Informed by F2 \\
\hline STEP 4 - Invitation to participate \\
\hline Informed by F1 and F7 \\
\hline STEP 5 - Start-up workshop \\
\hline Informed by F1, F2, F3, F4 and F6 \\
\hline STEP 6 - Manager communication \\
\hline Informed by F3, F4 and F7. \\
\hline Figure 1. The proposed framework comprises six steps synthesised from CoP literature. \\
\hline
\end{tabular}

Step 1 (S1): Manager Introduction. In Step 1, the promoter of the CoP introduces the responsible manager to the concept, with the purpose of establishing an interest and thus securing the necessary resource allocation and authority. The manager is informed about what a $\mathrm{CoP}$ is, $\mathrm{CoPs}$ in relation to workplace knowledge sharing and new knowledge creation, $\mathrm{CoP}$ management, resource allocation, 
and the necessity that the CoP be allocated decision-making authority in developing the practice. S1 is informed mainly by F3, F4, and F7.

Step 2 (S2): Practice definition. The manager is asked to identify a practice with two things in mind: First, a practice is a collection of tasks which can be identified as a job to complete (e.g., maintenance job X). Second, the goal is to choose a 'CoP topic' (Wenger et al., 2002) in which a sub-group of employees share an interest. The purpose is to identify a practice to which management will dedicate resources to develop and which employees are interested in. S2 is informed mainly by F5.

Step 3 (S3): Coordinator identification. A coordinator is identified among possible CoP participants and asked by the manager if he/she is interested. The coordinator must have deep practice experience and must be voluntary (e.g., perceive the $\mathrm{CoP}$ as an opportunity to develop a practice which he/she is passionate about). The coordinator is responsible for organising CoP meetings and updating the practice documentation so that knowledge can be distributed beyond the $\mathrm{CoP}$ and reach relevant employees. The coordinator's tasks are to arrange meetings, manage the new knowledge, and communicate with stakeholders. A written description of the responsibilities is given to the candidate, and she/he is informed that the role is completely informal and that all participants are equal. The coordinator is prepared through a discussion with the manager and later at the start-up workshop (S5) all participants must agree to the choice of coordinator. S3 is informed mainly by F2.

Step 4 (S4): Invitation to participate. The invitation to participate in the CoP is extended to employees via the organisation's preferred communication method. Participation must be voluntary and driven by personal interest. Participation entails two explicit requirements: an interest in sharing knowledge about the practice and experience with the practice with the purpose of attracting employees who will be active and participate with an open mind in conversations (Wenger et al., 2002). Those interested are requested to contact the manager. S4 is informed mainly by F1 and F7.

Step 5 (S5): Start-up workshop. Step 5 is a start-up workshop for the employees who expressed an interest in participating. The workshop participants are told that the purpose of the CoP is to share knowledge to improve a specific practice (defined in S2). The participants discuss, agree on, and inform the manager about a suitable meeting room, what resources they need, including the necessary ICT, and a CoP time schedule. The purpose is to support the CoP in requesting the needed resources for the group to work efficiently, and to enable the participants to decide collectively how to collaborate. S5 is informed mainly by F1, F2, F3, F4, and F6.

Step 6 (S6): Management communication. The coordinator is asked to record the minutes of each $\mathrm{CoP}$ meeting and email them to the manager sponsoring the $\mathrm{CoP}$ and $\mathrm{CoP}$ participants. The purpose of this process is to keep the sponsor and participants involved, particularly the manager, who must continuously allocate resources to the CoP. S6 is informed mainly by F3, F4, and F7. 


\section{Method}

The identified research gap shows the limited theoretical precedent of intentional CoP development within healthcare operations with empirical founded explanations of 'how' and 'why'. Hence, to answer the research question we adopted a case study research method as it allows for the investigation of a contemporary real-life phenomenon in a specific context and, in particular, for the study of explanatory answers to 'how' and 'why' events occurred (Yin, 2009). We used a single organisation double case study research method to test the framework and evaluate how and why the framework test resulted in the expected outcome (Yin, 2009). We chose a single organisation double case study to evaluate the framework in comparable settings. The case studies were conducted 10 months apart and for each of the two cases different practices were selected. In each case, an intentional CoP was initiated using the framework (see Figure 1). RJ was involved in S1 in case $\mathrm{A}$, in which he introduced the manager to CoP and the framework application. In case $\mathrm{B}, \mathrm{RJ}$ again participated in S1 and, additionally, what might be termed an 'action research' approach (Bryman \& Bell, 2011) was taken as RJ facilitated 'S5b: the start-up workshop'.

Case A and B followed the same method: Five to six weeks passed from S1 to step S6 and 13 weeks from S6 to evaluation workshop. The collected data for each case consisted of:

a) Written minutes of the CoP meetings.

b) A 'before' and 'after' implementation version of the guideline for the practice.

c) Recordings and documents from the evaluation workshop (see below and section Error! Reference source not found.).

d) Written notes of an interview with the coordinator to clarify and confirm intermediate findings.

The minutes of the COP meetings were written by the coordinator and emailed to the researchers, and document analysis was used to document and analyse CoP activity. 'Before' and 'after' versions of the guidelines were emailed to the researchers by the coordinator and compared to evaluate the CoP outcome. An effect modifier assessment (EMA) workshop with CoP participants identified events (interventions and non-interventions) which took place during the 13-week study period and evaluated their effect on the outcome (Edwards \& Winkel, 2018). The workshop was recorded, transcribed, and codified for analysis. Through the analysis, similar events were grouped into themes. In a telephone interview with the coordinator, findings from the EMA workshop and the identified guideline changes were discussed and qualified.

\subsection{Case context}

The blood analysis unit collects and analyses samples from patients at the hospital and in the area surrounding Northern Zealand, Denmark. The unit analyses approximately 3.5 million samples yearly; 29 employees (26 working in operations) work '24-7' in three shifts and one manager coordinates all activity. The analyses are done primarily by automated equipment; the employees' tasks are to keep the machine running and validate results. There are three categories of employees: Twenty-one 'operators' are responsible for daily operations; five 'specialists' are operators with additional responsibility for training and problem-solving, each for a specific piece of equipment; and three subject matter experts (SMEs) are responsible for updating guidelines and are not part of 
the daily operations. Prior to implementation of the guidelines, the SMEs developed the guidelines by writing drafts which the operators could read and provide feedback on, and subsequently the guideline was published to all employees.

Figure 2 illustrates the work environment at the 'STA-R' work station which is used approximately 250.000 times a year to analyse bloods coagulation capability. The operator performs a daily routine in which he/she cleans the machine, replaces needles, and refills reactors. The STA-R equipment was the focus for case A and in case B it was the equipment called Centaur.

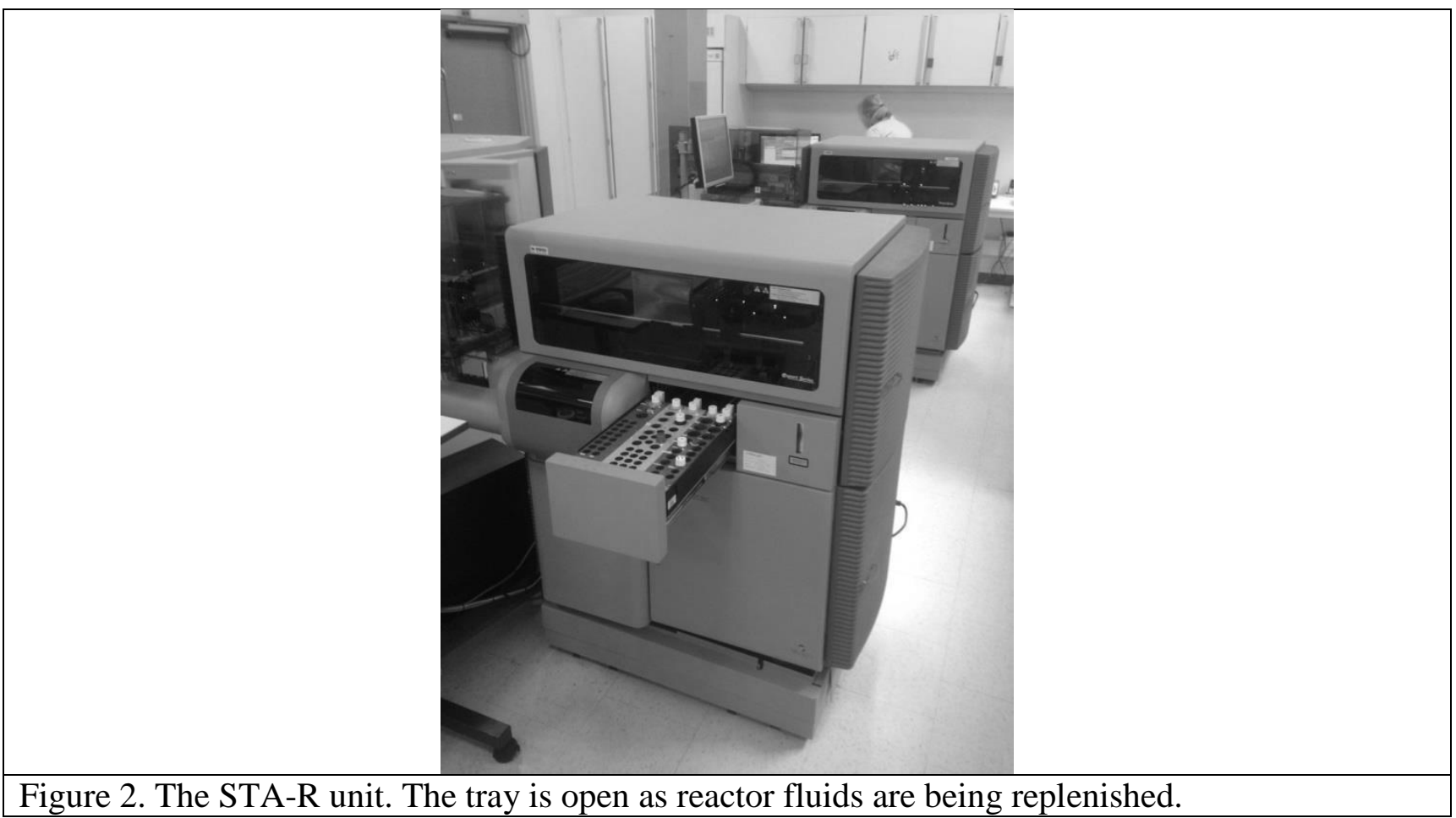

\section{Framework application}

The CoP promoter supported the manager by answering questions and participated in the manager meeting (S1) for both cases and in the start-up workshop (S5) for case 2. Several weeks passed from presentation (S2) to start-up workshop (S5) to allow time for people to plan their participation. The start-up workshop for case 2 was delayed for one week (week 6 instead of 5) due to a public holiday.

\subsection{Intervention process}

The six steps were followed for case A and case B as illustrated in Table 1. Case A took place in 2016 and case B in 2017.

Table 1. The Intervention Processes for cases A and B, Respectively

\begin{tabular}{|l|l|l|}
\hline Step & Case A & Case B \\
\hline $\begin{array}{l}\text { S1. The CoP was explained to the } \\
\text { manager and she agreed to participate. }\end{array}$ & Week 0 & Week 0 \\
\hline
\end{tabular}




\begin{tabular}{|c|c|c|}
\hline $\begin{array}{l}\text { S2. Practice identification by the } \\
\text { manager }\end{array}$ & Week 1 & Week 1 \\
\hline 2.b SME introduction & N/A & Week 1 \\
\hline $\begin{array}{l}\text { S3. Coordinator identification and } \\
\text { acceptance }\end{array}$ & Week 2 & Week 2 \\
\hline $\begin{array}{l}\text { S4. Presentation by the manager at the } \\
\text { monthly team meeting (approximately } \\
33 \% \text { of team present due to } 24-7 \text { shifts). } \\
\text { Later the same day an email was sent to } \\
\text { all employees. During the meeting the } \\
\text { employees could ask questions. }\end{array}$ & Week 3 & Week 2 \\
\hline $\begin{array}{l}\text { S4. Deadline for signing up with the } \\
\text { manager }\end{array}$ & Week 3 & Week 3 \\
\hline S5. Start-up workshop & Week 5 & N/A \\
\hline S5b: Facilitated start-up workshop & $\mathrm{N} / \mathrm{A}$ & Week 6 \\
\hline $\begin{array}{l}\text { S6. First CoP and manager } \\
\text { communication }\end{array}$ & Week 5 & Week 6 \\
\hline
\end{tabular}

S1. Manager introduction: The manager was provided with the same information in both cases during an introduction meeting with RJ.

S2. Practice definition: For both case A and case B the same definition was applied to define the practice. In case A the practice was a monthly maintenance task for the STA-R equipment, and for case B the practice was a daily start-up procedure for the Centaur equipment. The maintenance procedure in case A was chosen because the manager believed that many employees found it difficult. The start-up procedure for case B was chosen because in general it varied greatly depending on who performed it, and because the equipment created a bottleneck in production capacity.

Only case B: 2.b SME introduction: In case A there was no specific SME introduction. For case B the manager introduced the SME to the CoP by presenting the coordinator as a liaison, providing the CoP with decision-making authority in practice development, and explaining the CoP as an opportunity to have in-depth discussions with operators about the practice.

S3. Coordinator identification: In case A and case B the manager contacted an equipment specialist, and in each case the specialist agreed to be a CoP coordinator. The manager asked the specialist whether he/she wished to participate during a one-on-one meeting so that the specialist had the option to say no. The manager asked a specialist as the role is associated with a high individual skill level and is typically acknowledged by colleagues as being knowledgeable. Furthermore, the specialist is expected to participate in the development of the practice and guidelines for the equipment.

S4. Invitation to participate: In both case A and case B the presentation at a team meeting was followed by an email sent to all employees. A physical meeting with all employees was not possible due to '24-7' shifts and the costs associated with calling people to work outside their shift patterns. 
Additionally, the study aimed at testing the framework under the limitations of reality; consequently, the choice was made to utilise existing communication methods to reach $100 \%$ of the employees. Approximately 33\% participated in the meeting and the email reached $100 \%$, including those present at the meeting. The number of employees who volunteered in case A was four, and the number who volunteered in case B was 3 (see Table 2).

Table 2. CoP Activity and Participation Seniority for Cases A and B

\begin{tabular}{|c|c|c|}
\hline Participant ID & Number of meetings & Seniority \\
\hline \multicolumn{2}{|c|}{ Case A } \\
\hline 1 & 3 & 34 years \\
\hline 2 & 3 & 20 years \\
\hline 3 & 4 & 10 years \\
\hline 4 & 4 & 15 years \\
\hline \multicolumn{2}{|c|}{ Case B } \\
\hline 1 & 5 & 20 years \\
\hline 2 & 6 & 19 years \\
\hline 3 & 6 & $<3$ years \\
\hline
\end{tabular}

S5. Start-up workshop: In case A, four participants were present for the start-up workshop and the participants subsequently sent a time schedule to the manager and requested a meeting room. In case B, three participants were present at the start-up workshop. The participants finished the time schedule after the meeting and emailed it to the manager together with a meeting room request.

Only case B: S5b: Facilitated start-up workshop. The CoP promoter (RJ) facilitated the start-up workshop and explored how participants would characterise a good knowledge-sharing collaboration; subsequently, the participants did as described in S5.

S6. Manager communication: In both case A and case B the coordinator continuously emailed a brief summary of the meeting to the participants, manager, and the researcher.

\section{Results}

\subsection{CoP activity}

In both case A and case B the framework test resulted in the development of a CoP (see Table 2). In case A, four employees volunteered and in the course of the 13 weeks, four meetings took place. In case B, three employees volunteered and during the 13 weeks they met five times and the coordinator was absent for one meeting because of a holiday.

\subsection{CoP knowledge sharing}

In both cases, the CoP participants reported having conversations which explored differences and similarities in the participants' ways of working. The participants willingly shared their individual knowledge with each other and, furthermore, differences in their approaches were explored and became opportunities from which to learn. 
'During the meetings we discussed our different approaches'.

'...by talking about why we do as we do we get things talked thoroughly through'.

'In the group we have shared our experience, what we do, and why we do it'.

The participants in case B made similar statements. The CoP provided the participants with a forum for interacting which was characterised by additional time to talk together about their work within the specific practice:

'Changes to a procedure are difficult to talk about during work. The meetings provide the opportunity to sit and talk. This is necessary when changing a procedure'.

'I think it has been positive being part of the group and I think that I have learned a lot. I find it to have been a positive experience. It has been good trying a different form of collaboration'.

'We're not used to talking so much about things. We're just used to acting'.

\subsection{Practice improvement and guideline changes}

In both cases the practice changed notably in terms of task sequence, and the guidelines describing the practice notably changed in terms of different use of illustrations.

\subsubsection{Illustrations}

Screen dumps from the software and pictures from the equipment have increased. For case A, the old guidelines contained no pictures and 20 screen dumps, while the new guidelines include six pictures and 19 screen dumps. In case B, the guideline went from having no pictures to including 6 pictures, while the use of screen dumps did not differ. An example of the pictures used in the new guidelines for cases A and B can be seen in Figure 3.
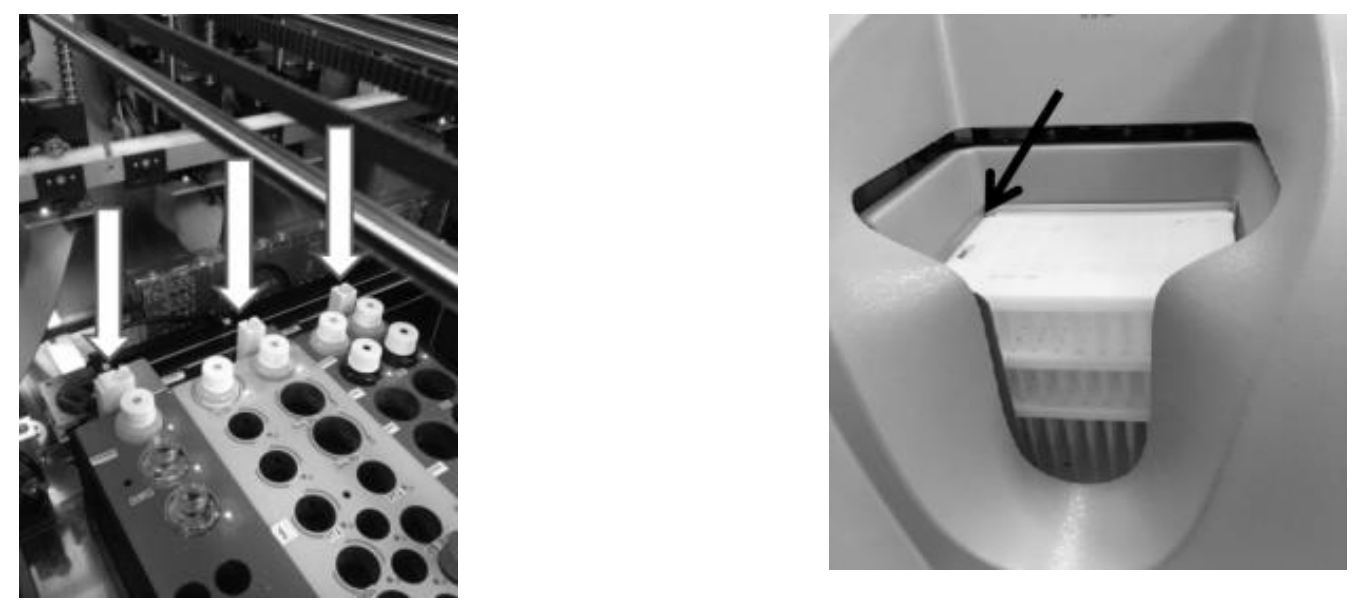
Figure 3. Left: Case A - The white arrows show the positions of three wells inside the STA-R. Right: Case B - The black arrow indicates the maximum refilling level of the white plastic plates. Both pictures were taken and edited by participants.

When asked about the use of pictures in the guidelines, the coordinator replied:

'Pictures make it easier to know what to do. When you haven't done the maintenance for a while, then it can be difficult to remember what the "well" is when you have to refill hypochlorite. A picture makes it easier to follow the guideline'.

\subsubsection{Changed task sequences}

The new guidelines for case A show a noticeable change of sequence: The task of 'cleaning needles' is placed before 'cleaning wells', whereas the old guidelines described this in the opposite order. The coordinator gave the following explanation for the change:

Cleaning wells is only done weekly and therefore something you rarely do, leaving many insecure about it. Maybe they do it every six months. Cleaning needles is done every day, so you know it and feel confident about doing it. So instead of starting with the difficult task we now start with the easy, then you can clean the needles and go for your coffee break and then start the well cleaning.

The reason for the change in sequence was knowledge about how participants felt about the task while completing it, and participants identified the task sequence they felt most confident with. Another possible explanation for the change in sequence is that the new sequence places the difficult task (cleaning wells) before the coffee break; the coordinator explained that the coffee break offers employees an opportunity to 'ask for help' because the operators assemble for their coffee breaks. The change in sequence was motivated by consideration of the fact that operators rarely do the maintenance job.

In case $\mathrm{B}$, the old guidelines specified that two tasks (one automated and one manual) were to be done sequentially. One participant (number 1) did this; however, the other two participants (number 2 and 3) performed the two tasks in parallel, which solved the same task in a shorter amount of time. The author of the old guidelines (the SME) considered the parallel approach to be too complex for operators and felt that it posed a threat to quality; consequently, she used the sequential description in the guidelines. Participants 2 and 3 considered the sequential approach a waste of time, and began to experience stress about the manual job as they knew the machine was 'waiting' for the operator to finish; consequently, participant 2 and 3 used the parallel approach. The new guidelines described the parallel approach.

\section{Discussion}

The purpose of this study was to propose and test a framework for intentional CoP development within operations, with the expected outcome of knowledge sharing, new knowledge creation, and 
practice improvement. The framework test resulted in meetings in which knowledge sharing took place and guidelines were changed. This section discusses these results using CoP theory.

\subsection{Is it a CoP or not?}

In both cases a small group of people (three and four in case A and case B, respectively) held a number of meetings and communicated between meetings during the study period. To discuss whether the groups can be considered CoPs, the present authors will refer first to quantitative and then to qualitative characteristics.

Three or four participants could be considered a small number compared with the 26 employees (including the CoP participants) who perform the practice or with past empirical CoP studies. With regard to the latter, few studies have clearly indicated the number of $\mathrm{CoP}$ members or the size of the possible recruiting group, meaning that a quantitative comparison can be based only on estimates and interpretation. A CoP is used with a smaller group of people (three to six) discussing work over coffee (e.g., (Orr, 1996; Schenkel \& Teigland, 2008), several people (five to 20) meeting for organised events (e.g., (Akkerman et al., 2008; Wolf et al., 2011), or a large group (20+) of employees (e.g., (Iaquinto et al., 2011). Compared with these numbers the framework test attracted just enough employees. Furthermore, if the extensive seniority (see Table 2) of the participants is considered to be a mark of the specialist within the practice then the CoP label is suitable (Wenger et al., 2002).

To discuss the qualitative characteristics of the meetings, the authors refer to the CoP definition of Wenger et al. (2002): a 'group of people who share a concern, a set of problems, or a passion about a topic, and who deepen their knowledge and expertise in this area by interacting on an ongoing basis'. The study relied on voluntary participation, and the invitation to participate (S4) specified that participation required 'an interest in sharing knowledge about the practice'. As participation was voluntary and framed by a pre-defined practice it can be concluded that participants genuinely shared 'a passion' for the practice and a willingness to share knowledge. Furthermore, during the study period (Table 2) participants had ongoing interactions, during which they shared knowledge and developed their individual practice as well as the guidelines. The conversations between participants are of particularly relevance when characterising the meetings, and the participants stated that different approaches were shared, discussed, and integrated, resulting in one common approach (see Section 5.2, p. 10). This type of conversation is typical for a CoP which facilitates the negotiated development of practice through sharing stories (Hislop, 2013; Wenger et al., 2002).

In both cases the CoP was responsible for updating the guidelines with their improvements to practice, to avoid a discrepancy between the tasks done and the written documentation. While the CoP conversations have the characteristics of knowledge sharing and development through 'interpreting' and integrating' (Crossan, Lane, \& White, 1999), organisational knowledge utilisation requires that knowledge is disseminated beyond the $\mathrm{CoP}$ to all employees doing the practice. A written guideline is one method for doing this (Cordery et al., 2015; Nilsen, 2015). However, the guideline responsibility raises the question of whether the framework test developed a CoP or a temporary team. Based on the differences between a CoP and a team (McDermott \& Archibald, 
2010), the authors confirmed that two CoPs were developed. First, in both cases a collaborative effort took place and, while the coordinator had a supportive responsibility, he/she had no formal power. All participants were equal in terms of contributing to defining the practice, sharing knowledge, and choosing how to collaborate in the CoP. Second, the CoP was not charged with solving a specific problem; instead, the $\mathrm{CoP}$ was primarily responsible for developing knowledge to improve tomorrow's work day and reach beyond the CoP. Third, the guideline changes were the outcome of the CoP developing the practice. Finally, the time span was not specified in advance as participants were charged with developing knowledge and updating the guideline. It is certain that the level of activity was greatly reduced after the 13-week period ended, but the CoP continues to exist, as members continue to interact and share knowledge embedded in their daily work.

\subsection{Framework evaluation}

At the end of each study period an EMA workshop with CoP participants was used to evaluate how the framework contributed to CoP development. During the workshop the participants were asked to identify any noteworthy events which took place in the unit during the study period and to elaborate on the effect of the events. In the subsequent analysis the events were grouped into themes and linked to the framework steps when possible. The result of the analysis is described in the following section in four themes: Themes 1, 2, and 3 are the events directly linkable to framework steps, while theme 4 contains events which are indirectly relatable to the framework.

\subsubsection{Theme 1: The invitation to participate voluntarily}

Employees from both cases found that the invitation to participate voluntarily in the CoP, which was sent to employees, had a positive influence on their motivation to participate in a CoP. When the participants were invited to participate voluntarily, the pre-existing relationships and individual interest were leveraged, thus reducing the instrumentality of the framework (Wenger et al., 2002). The intervention is appropriate for an organisation in which operations employees share a physical workplace, resources are scarce, and a CoP must adjust its activity level according to the organisational need. However, the study did not analyse how organisational culture influenced the framework test and outcomes.

The participants from both cases mentioned the team meeting as the place where they became aware of the possibility of participating, whereas none mentioned the invitation received via email. This could be due to email being a passive dissemination method, whereas a face-to-face team meeting is an active dissemination approach which allows for richer communication by, for example, offering the opportunity to ask and clarify questions (Nilsen, 2015). A shared meeting with an open conversation also facilitates shared meaning-making among employees, which provides a means to address any confusion or misunderstanding caused by the introduction of the new term 'CoP' (Zack, 2000). Within an operations unit with a '24-7' shift plan, limited opportunities are available to gather employees and few resources exist to manage communication, and these contextual limitations must be considered in a $\mathrm{CoP}$ development framework for operations.

The importance of voluntary participation relates to 'S4: Invitation to participate', which the authors consider to be an important $\mathrm{CoP}$ development step. 


\subsubsection{Theme 2: The coordinator arranging meetings and implementing changes}

The coordinator was in charge of coordinating the $\mathrm{CoP}$ meetings and documenting the practice improvements in the guideline. Furthermore, the coordinator collaborated with the SME, acting as a knowledge broker who bridged the gap between the practice-based knowledge of operations employees and the theoretical knowledge of the SME (Wenger, 2000). The job of the coordinator was identified by participants as important in case A; however, case B participants did not mention the coordinator. Still, the coordinator collaborated with the SME, coordinated meetings, and implemented practice improvements in the guideline; consequently, the authors consider the identification of a coordinator an important step for $\mathrm{CoP}$ development. That case B participants did not mention the coordinator indicates that the coordinator remained in the background, ensured that the CoP had a time and a place to meet, and allowed the CoP to work. The CoP was a small group with good pre-existing relationships, leaving little need for the coordinator to intervene. Consequently 'S3: Coordinator identification' is considered an important step.

\subsubsection{Theme 3: Having meetings in an undisturbed room}

Organisational support in the form of resource allocation to the CoP was in the two cases translated into allocation of time to meet, a meeting room, and the necessary ICT. The CoP mainly interacted in meeting rooms near the practice. The participants considered the allocation of a meeting room important, as the room provided an undisturbed space allowing the participants to engage in indepth discussions in which questions could be asked and conversation unfold. One understanding of interactions is that they are embedded in the actual work (Gabbay \& le May, 2004; Lave \& Wenger, 1991) and another is that they take place within a safe environment in which ideas can be freely exchanged (Orr, 1996). The results of this study support the understanding brought forward by Orr (1996) as the work environment in the study is busy and a quiet room is needed to make in-depth conversations possible.

Neither case A nor case B identified the allocation of time to meet as important. However, from the meeting minutes it can be seen that the CoP meetings were difficult to plan because of the '24-7' shifts of employees, and some meetings took place in which participants arrived at work before their scheduled shift and began to participate. Consequently, the authors consider allocation of time for $\mathrm{CoP}$ participation an important step. One approach to this is to take employees 'off the line' and prioritise $\mathrm{CoP}$ participation. Another approach is to allow overtime for employees to participate before or after their shifts.

In total the authors can confirm that resource allocation is as important within operations as in other contexts, and the study highlights the necessity of addressing resource allocation, and specifically a meeting room, during 'S1: Manager Introduction'.

\subsubsection{Theme 4: Beyond noteworthy events}

The participants did not identify events directly relatable to 'S2: Practice Definition'. However, S2 is indirectly linked with 'S3: Coordinator identification' and 'S4: Invitation to participate' as the 
choice of practice defines the work experience which makes CoP participation meaningful (Wenger et al., 2002). Furthermore, it is not surprising that events relatable to $S 2$ were not identified, as the participants were not involved in this step. Consequently, S2 is considered important for CoP development.

Particularly for case B, the SME was given an introduction (S2b), and in contrast to case A, where there was tension between the CoP and the SME, in case B the SME's involvement had the character of collaboration. One possible explanation for this is that in case B the SME was explicitly told that the $\mathrm{CoP}$ was responsible for developing the practice during S2b, whereas in case A it is possible that the SME was not aware of the changed responsibility because she was not given a specific introduction. However, both the SME and the CoP participants in cases A and B were different individuals, which also could have influenced the collaboration. Consequently, the importance of S2b remains uncertain.

The case A participants did not identify events related to the start-up workshop, and while the case B participants identified the facilitated start-up workshop (S5b), they considered it to be relatively unimportant. A possible hypothesis is that a start-up workshop will have a greater impact if participants are less familiar with each other and therefore have a lower cultural proximity (Scarso et al., 2009).

The participants did not identify events directly relatable to 'S6: Manager communication'. The importance of 'S6: Manager communication' requires a longer study period to understand properly, as the consequence of keeping the sponsor informed is expected to influence the ongoing resource allocation.

Summary steps 1) 'Manager introduction', 2) 'Practice definition', 3) 'Coordinator identification' and 4) 'Invitation to participate' were found to be important for CoP development, whereas the importance of the SME introduction (S2b) is uncertain but likely important (Table 3). Furthermore, the importance of a start-up workshop which is facilitated or not (S5 and S5b), respectively, and manager communication (S6) is undetermined.

Table 3. The steps marked with an ' $\mathrm{X}$ ' were found to be important and the step marked with an ( $\mathrm{x}$ ) is most likely important, whereas steps marked with '?' require further study.

\begin{tabular}{|l|c|c|c|c|c|c|c|c|}
\hline & S1 & S2 & S2b & S3 & S4 & S5 & S5b & S6 \\
\hline Summary & $\mathrm{X}$ & $\mathrm{X}$ & $(\mathrm{x})$ & $\mathrm{X}$ & $\mathrm{X}$ & $?$ & $?$ & $?$ \\
\hline
\end{tabular}

\section{Conclusion}

This paper proposed a framework for intentional CoP development structured in six steps and informed by seven factors for CoP development as identified in the literature. A double test in a blood analysis unit working '24-7' resulted in the successful development of two CoPs. Manager introduction, choosing the practice on which the CoP should focus, identifying a coordinator, and inviting employees to participate voluntarily are important steps that can be used to intentionally 
develop a CoP. An important result of the framework test was the CoP participants' knowledge sharing and new knowledge creation through conversations in which individual knowledge was interpreted and integrated into new collective knowledge. Furthermore, the study demonstrates that the new knowledge created improves the practice, and in the specific context also improves the guidelines describing the practice.

The study has implications both for scholars and managers.

From an academic perspective, first, it confirms the findings of previous literature that a manager's support plays a vital role in developing a CoP by allocating the necessary resources in terms of time for CoP participation, ICT, and meeting facilities. The study finds that the manager can be engaged through a presentation given by a CoP promoter.

Second, the study confirms the importance of voluntary participation and found that by having the manager pre-define a practice and then inviting employees to participate voluntary can engage employees in the CoP. Face-to-face communication is found to be more effective when recruiting $\mathrm{CoP}$ participants compared with email; however, the face-to-face method provides a limited reach of receivers in cases of '24-7' shifts. Future studies should explore how a recruitment campaign can be communicated with high reach and impact and still be feasible for an operations manager

Third, the study confirms that the role of CoP coordinator is important, and the study found that the role can be introduced by having a manager recruit a skilled and respected employee to undertake the role voluntarily. However, further studies are needed to understand how different stakeholders collaborate in knowledge sharing, as suggested by the interaction between the SME and CoP, as this interaction proved both a source of inspiration and an ignitor of conflict.

From a business perspective, the study offers a useful step-by-step tool for managers who want to support the development of a $\mathrm{CoP}$, and also indicates to them what factors are particularly important to the development of a successful $\mathrm{CoP}$ and therefore deserve special attention (e.g., voluntarism, a dedicated meeting room).

The main limitation of the study is that it involved a single organisation, which restricts the generalisability of the results. Moreover, a longer study period would be needed to understand the long-term effect of the framework. Additionally, a more thorough understanding of the impact of the framework should include the analysis of process data to document changes in process improvement or, in the healthcare sector, patient care. Finally, the study focussed on the operations level; hence, future research should consider the tactical and strategic levels to investigate how and why organisation choose to intentionally develop CoPs, and how CoPs fit into a knowledge management strategy.

Despite these limitations, the study found that its proposed framework can be used to intentionally develop CoPs within operations, and that the proposed framework offers specific guidance which is the main contribution to the CoP field. 


\section{References}

Akkerman, S., Petter, C., \& Laat, M. de. (2008). Organising communities-of-practice: facilitating emergence. Journal of Workplace Learning, 20(6), 383-399.

Aljuwaiber, A. (2016). Communities of practice as an initiative for knowledge sharing in business organisations : a literature review. Journal of Knowledge Management, 20(4), 731-758.

Barbour, L., Armstrong, R., Condron, P., \& Palermo, C. (2018). Communities of practice to improve public health outcomes: a systematic review. Journal of Knowledge Management, $22(2), 326-343$.

Barwick, M. A., Peters, J., \& Boydell, K. (2009). Getting to uptake: Do communities of practice support the implementation of evidence-based practice? Journal of the Canadian Academy of Child and Adolescent Psychiatry, 18(1), 16-29.

Bhattacharyya, O., Reeves, S., \& Zwarenstein, M. (2009). What Is Implementation Research? Research on Social Work Practice, 19(5), 491-502.

Borzillo, S. (2009). Top management sponsorship to guide communities of practice. Journal of Knowledge Management, 13(3), 60-72.

Bryman, A., \& Bell, E. (2011). Business Research Methods (3rd ed.). New York: Oxford University Press.

Conklin, J., Lusk, E., Harris, M., \& Stolee, P. (2013). Knowledge brokers in a knowledge network: the case of Seniors Health Research Transfer Network knowledge brokers. Implementation Science, 8(1), 7.

Cordery, J. L., Cripps, E., Gibson, C. B., Soo, C., Kirkman, B. L., \& Mathieu, J. E. (2015). The Operational Impact of Organizational Communities of Practice: A Bayesian Approach to Analyzing Organizational Change. Journal of Management, 41(2), 644-664.

Crossan, M. M., Lane, H. W., \& White, R. E. (1999). An Organizational Learning Freamwork: From Intuition to Institution. Academy of Management Review, 24(3), 522-537.

Edwards, K., \& Winkel, J. (2018). A method for effect modifier assessment (EMA) in ergonomic intervention research. Applied Ergonomics, 72, 113-120.

Fung-Kee-Fung, M., Boushey, R. P., \& Morash, R. (2013). Exploring a "community of practice" methodology as a regional platform for large-scale collaboration in cancer surgery - the Ottawa approach. Current Oncology, 21(1), 13.

Fung-Kee-Fung, M., Boushey, R. P., Watters, J., Morash, R., Smylie, J., Morash, C., ... Sundaresan, S. (2013). Piloting a regional collaborative in cancer surgery using a "community of practice" model. Current Oncology, 21(1), 27.

Gabbay, J., \& le May, A. (2004). Evidence based guidelines or collectively constructed "mindlines?" Ethnographic study of knowledge management in primary care. British Medical Journal (Clinical Research Edition), 329(level 2), 1013.

Hemmasi, M., \& Csanda, C. M. (2009). The Effectiveness of Communities of Practice : An Empirical Study. Journal of Managerial Issues, XXI(2), 262-279. 
Hislop, D. (2013). Knowledge Management in Organizations - A Critical Introduction (Third ed.). New York: Oxford University Press.

Iaquinto, B., Ison, R., \& Faggian, R. (2011). Creating communities of practice: scoping purposeful design. Journal of Knowledge Management, 15(1), 4-21.

Kislov, R., Walshe, K., \& Harvey, G. (2012). Managing boundaries in primary care service improvement: A developmental approach to communities of practice. Implementation Science, 7(1), 97.

Lave, J., \& Wenger, E. (1991). Situated Learning : Legitimate Peripheral Participation (1st ed.). Cambridge, UK: Cambridge University Press.

Lesser, E. L., \& Storck, J. (2001). Communities of practice and organizational performance. IBM Systems Journal, 40(4), 831-841.

Li, L. C., Grimshaw, J. M., Nielsen, C., Judd, M., Coyte, P. C., \& Graham, I. D. (2009). Use of communities of practice in business and health care sectors: A systematic review. Implementation Science, 4(1), 27.

McDermott, R., \& Archibald, D. (2010). Harnessing Your Staff's Informal Networks. Harvard Business Review, 88(3), 82-89.

McKellar, K. A., Pitzul, K. B., Yi, J. Y., \& Cole, D. C. (2014). Evaluating communities of practice and knowledge networks: A systematic scoping review of evaluation frameworks. EcoHealth, 11(3), 383-399.

Nilsen, P. (2015). Making sense of implementation theories, models and frameworks. Implementation Science, 10(1), 53.

Orr, J. E. (1996). Talking about machines : An ethnography of a modern job. Cornell University Press.

Perrott, B. (2015). Including Consumers in the Organisational Knowledge Network. Knowledge and Process Management, 22(4), 288-296.

Probst, G., \& Borzillo, S. (2008). Why communities of practice succeed and why they fail. European Management Journal, 26(5), 335-347.

Ranmuthugala, G., Plumb, J. J., Cunningham, F. C., Georgiou, A., Westbrook, J. I., \& Braithwaite, J. (2011). How and why are communities of practice established in the healthcare sector? A systematic review of the literature. BMC Health Services Research, 11(1), 273.

Rowley, E., Morriss, R., Currie, G., \& Schneider, J. (2012). Research into practice : Collaboration for Leadership in Applied Health Research and Care ( CLAHRC) for Nottinghamshire , Derbyshire, Lincolnshire ( NDL ). Implementation Science, 1-11.

Scarso, E., Bolisani, E., \& Salvador, L. (2009). A systematic framework for analysing the critical success factors of communities of practice. Journal of Knowledge Management, 13(6), 431447.

Schenkel, A., \& Teigland, R. (2008). Improved organizational performance through communities of practice. Journal of Knowledge Management, 12(1), 106-118. 
http://doi.org/10.1108/13673270810852421

Verburg, R. M., \& Andriessen, J. H. E. (2006). The assessment of communities of practice. Knowledge and Process Management, 13(1), 13-25.

Wenger, E. (2000). Communities of Practice and Social Learning Systems. Organization, 7(2), 225-246.

Wenger, E. (2004). Knowledge management as a doughnut: shaping your knowledge strategy through communities of practice. Ivey Business Journal Online, 68(3).

Wenger, E., Snyder, W. M., \& McDermott, R. (2002). Cultivating Communities of Practice : A Guide to Managing Knowledge. Boston, MA: Harvard Business School Press.

Wolf, P., Späth, S., \& Haefliger, S. (2011). Participation in intra-firm communities of practice: a case study from the automotive industry. Journal of Knowledge Management, 15(1), 22-39.

mklin, S., \& Igel, B. (2012). Communities of Practice Purposefully Designed for Improving Business Performance. Knowledge and Process Management, 19(4), 189-202.

Yin, R. K. (2009). Case Study Research: Design and Methods. Applied social research methods series (5th ed.).

Zack, M. H. (2000). If Managing Knowledge is the Solution, then What's the Problem? In Y. Malhotra (Ed.), Knowledge Management and Business Model Innovation (1st ed., pp. 16-36). 